\title{
Influence of mild and moderate hepatic impairment on axitinib pharmacokinetics
}

\author{
Michael A. Tortorici • Melvin Toh • S. V. Rahavendran • Robert R. LaBadie • \\ Christine W. Alvey $\cdot$ Thomas Marbury $\cdot$ Ernesto Fuentes • Matthew Green • \\ Grace Ni • Brian Hee $\cdot$ Yazdi K. Pithavala
}

Received: 16 April 2010 / Accepted: 15 June 2010 / Published online: 2 July 2010

(C) The Author(s) 2010. This article is published with open access at Springerlink.com

\begin{abstract}
Summary Objective: To evaluate the effects of hepatic impairment on the pharmacokinetics and safety of a single, oral axitinib dose in subjects with mild or moderate hepatic impairment. Methods: In this phase I, open-label, parallelgroup study, a total of 24 subjects with either normal hepatic function $(n=8)$ or with mild $(n=8)$ or moderate $(n=$ 8 ) hepatic impairment were administered a single, oral dose of axitinib $(5 \mathrm{mg})$. Blood samples were collected at intervals up to $144 \mathrm{~h}$ following dosing, and plasma pharmacokinetics and safety were assessed. Changes in
\end{abstract}

Funding: This study was sponsored by Pfizer Inc.

M. A. Tortorici $(\bowtie) \cdot$ M. Toh $\cdot$ S. V. Rahavendran $\cdot$ B. Hee $\cdot$

Y. K. Pithavala

Pfizer Oncology,

10555 Science Center Drive,

San Diego, CA 92121, USA

e-mail: michael.tortorici@pfizer.com

R. R. LaBadie $\cdot$ C. W. Alvey • M. Green · G. Ni

Pfizer Oncology,

50 Pequot Avenue,

New London, CT 06320, USA

T. Marbury

Orlando Clinical Research Center,

5055 S.Orange Avenue,

Orlando, FL 32809, USA

E. Fuentes

Elite Research Institute,

15705 NW 13th Avenue,

Miami, FL 33169, USA

Present Address:

M. Toh

CK Life Sciences,

2 Dai Fu Street,

Tai Po, Hong Kong axitinib plasma exposures in subjects with mild or moderate hepatic impairment were predicted using computer simulations and used to guide initial dosing in the clinical study. Results: Axitinib exposure was similar in subjects with normal hepatic function and those with mild hepatic impairment, but approximately twofold higher in subjects with moderate hepatic impairment. Axitinib exposure weakly correlated with measures of hepatic function but was not affected by smoking status. Axitinib protein binding was similar in the three treatment groups. No significant treatment-related adverse events were reported. Conclusions: Compared with subjects with normal hepatic function, moderate hepatic impairment increased axitinib exposure, suggesting that the oral clearance of axitinib is altered in these subjects. In addition, these data indicate a possible need for a dose reduction in subjects who develop moderate or worse hepatic impairment during axitinib treatment. A single 5-mg dose of axitinib was well tolerated in subjects with mild or moderate hepatic impairment.

Keywords Axitinib P Pharmacokinetics · Tolerability · Hepatic impairment Vascular endothelial growth factor

\section{Introduction}

Axitinib is an oral, potent, and selective inhibitor of vascular endothelial growth factor (VEGF) receptors 1, 2, and 3 [1]. Early clinical trial experience has demonstrated that it has activity and is well tolerated as a single agent and in combination with chemotherapy for the treatment of a number of tumor types, including renal cell carcinoma [2, 3], thyroid cancer [4], and non-small cell lung cancer [5]. Axitinib is currently in phase III development for advanced renal cell carcinoma. 
In the clinic, axitinib is administered at a 5-mg twicedaily, oral starting dose. The pharmacokinetics of axitinib are linear within the $5-10 \mathrm{mg}$ clinical-dose range as assessed by single-dose administration in healthy volunteers and characterized by an oral absolute bioavailability of $58 \%$, rapid oral absorption (with peak plasma concentrations occurring 3-6 $\mathrm{h}$ after dosing in the fed state), and a terminal phase plasma half-life $\left(\mathrm{t}_{1 / 2}\right)$ of $3-5 \mathrm{~h}$ [6]. The plasma protein binding of axitinib is $>99 \%$; in vitro studies indicate that axitinib binds strongly to albumin and, to a lesser extent, to $\alpha-1$-acid glycoprotein (unpublished data).

Axitinib is metabolized primarily by oxidation via cytochrome P450 (CYP) 3A4/5, and to a lesser extent by CYP1A2, CYP2C19, and glucuronidation via the uridine diphosphate-glucuronosyltransferase (UGT) 1A1 pathway (unpublished data). In a human mass balance study, 30$60 \%$ of the administered radiolabeled axitinib oral dose was eliminated in feces, with renal elimination accounting for a further $23 \%$ (unpublished data). No unchanged axitinib was found in urine samples; all urinary radioactivity was related to axitinib metabolites. Metabolic profiling of fecal samples indicated that unchanged axitinib was the predominant radioactive component. Together, these data indicate that hepatobiliary excretion is the major elimination pathway for axitinib. Thus, a clinical study to characterize changes in axitinib exposure with hepatic impairment was warranted. To assist in the design of the clinical study and to select appropriate dosing, simulations were conducted using the Simcyp ${ }^{\circledR}$ Population-based Absorption, Distribution, Metabolism, and Excretion (ADME) Simulator (Simcyp ${ }^{\circledR}$ Ltd, Sheffield, UK) [7] to predict changes in axitinib plasma exposure in subjects with varying degrees of hepatic impairment.

The primary objectives of the present phase I study were to (1) evaluate the effect of hepatic impairment on axitinib pharmacokinetics and (2) assess safety and tolerability of a single oral 5-mg axitinib dose in subjects with mild or moderate hepatic impairment. Since VEGF is central to one of the target pathways for axitinib and plays a major role in wound healing, subjects with severe hepatic impairment were not included due to presumed mechanism-based risk of bleeding events and coagulopathy.

\section{Methods}

Prestudy Simcyp simulation of the effect of hepatic impairment on axitinib exposure

In order to assist in the development of the clinical study, predictions of the effects of hepatic impairment on the pharmacokinetics of axitinib were conducted using Simcyp Population-Based ADME Simulator version 8.2 SP2. The model for hepatic impairment was developed using parameters obtained from preclinical assessments as well as built-in software assumptions and standard physiological parameter estimates. Plasma concentrations expected after administration of a single $5-\mathrm{mg}$ oral dose of axitinib in subjects with normal hepatic function or mild or moderate hepatic impairment were simulated in ten clinical trials (with ten subjects per clinical trial) under fed conditions using a one-compartmental distribution and first-order absorption model.

Input parameters specific to axitinib estimated in vitro included the apparent intrinsic clearance for each recombinant CYP isoform: CYP3A4 (maximum velocity $\left[\mathrm{V}_{\max }\right]$ : $9.6 \mathrm{pmol} / \mathrm{min} / \mathrm{pmol}$ of isoform; Michaelis-Menten constant $\left.\left[\mathrm{K}_{\mathrm{m}}\right]: 4 \mu \mathrm{M}\right)$, CYP3A5 $\left(\mathrm{V}_{\max }: 1.41 \mathrm{pmol} / \mathrm{min} / \mathrm{pmol}\right.$ of isoform; $\left.\mathrm{K}_{\mathrm{m}}: 1.9 \mu \mathrm{M}\right)$, CYP2C19 ( $\mathrm{V}_{\text {max }}: 0.11 \mathrm{pmol} / \mathrm{min} /$ pmol of isoform; $\mathrm{K}_{\mathrm{m}}: 5.9 \mu \mathrm{M}$ ), and CYP1A2 (apparent intrinsic clearance: $0.17 \mu \mathrm{L} / \mathrm{min} / \mathrm{pmol}$ of isoform); the $V_{\max }$ and $\mathrm{K}_{\mathrm{m}}$ for UGT1A1 (132.5 pmol/min/mg of microsomal protein and $44.2 \mu \mathrm{M}$, respectively); fraction unbound in plasma (0.010); blood-to-plasma partition coefficient (0.79); fraction absorbed (1.0); - $\log _{10}$ dissociation constant (4.2); absorption rate $(1.98 \mathrm{~L} / \mathrm{h})$; and volume under steady state conditions $(1 \mathrm{~L} / \mathrm{kg})$. Based on observations from a human mass balance study (unpublished data), the renal clearance for axitinib was assigned a value of zero. The Simcyp hepatic-impairment model assumes that the activity of CYP isoforms decreases with worsening hepatic function, specifically, that the activity of CYP3A4/5 is decreased by $42 \%$ and $62 \%$ in mild and moderate hepatic impairment, respectively, compared with normal hepatic function.

\section{Study design}

This phase I, open-label, single-dose, parallel-group study assessed the pharmacokinetics, safety, and tolerability of a 5-mg single oral dose of axitinib in subjects with normal hepatic function or mild or moderate hepatic impairment according to the US Food and Drug Administration (FDA) guidelines on hepatic impairment studies [8]. The study was carried out at two centers (Orlando, FL, and Miami, FL) from May 16, 2008, to October 26, 2008.

\section{Subjects}

Participants were male or female subjects aged $\geq 18$ years with normal hepatic function or mild or moderate hepatic impairment, according to the Child-Pugh (CP) classification $[9,10]$. Subjects were screened for participation within 21 days prior to the first dose of study treatment. Subjects with normal hepatic function were recruited after subjects with mild $(\mathrm{CP}$ class A [CP-A] score 5-6) and moderate (CP class B [CP-B] score 7-9) hepatic impairment had completed the study. In 
all, eight subjects enrolled into each of the three groups. Control subjects with normal hepatic function were matched to subjects with hepatic impairment based first on weight, and then on age and gender. In order to match subjects based on body weight, four of the subjects with normal hepatic function were matched to four subjects in each of the mild and moderate hepatic-impairment groups. Individual subjects to match were those with the lowest $(n=1)$, highest $(n=1)$, and median $(n=2)$ weights $( \pm 10 \mathrm{~kg})$ in each hepatic-impaired group. After matching subjects with normal hepatic function by body weight, they were then matched for age ( \pm 10 years) and gender to subjects with mild or moderate hepatic impairment.

Subjects with normal hepatic function were required to be healthy, defined as no clinically relevant abnormalities, which were identified by a detailed medical history and full physical examination, including blood pressure, pulse rate, 12-lead electrocardiogram (ECG), and clinical laboratory tests. Liver function tests, albumin, and prothrombin time were all required to be within normal range. Eligible subjects had a body mass index (BMI) of $18-32 \mathrm{~kg} / \mathrm{m}^{2}$ and a total body weight $>50 \mathrm{~kg}$.

Subjects with hepatic impairment were required to have hepatic dysfunction due to hepatocellular disease (not secondary to other diseases) as documented by medical history, physical examination, liver biopsy, hepatic ultrasound, computed tomography scan, or magnetic resonance imaging, and have adequate renal function, determined by a 24-h creatinine clearance $>75 \mathrm{ml} / \mathrm{min}$. Hepatic dysfunction was required to be stable, defined as no clinically significant change in disease status within the last 30 days, which was documented by recent medical history, including no worsening of clinical signs of hepatic impairment or no worsening of total bilirubin or prothrombin time $>50 \%$. Subjects with hepatic impairment also had to be on a stable treatment regimen or dose of medication, or a fluctuating treatment regimen if the underlying disease was under control, provided sponsor approval was granted prior to the first dose of study treatment. In addition to the general exclusion criteria for all groups outlined below, exclusion criteria specific to subjects with hepatic impairment included any other clinically significant diseases that contraindicated the use of axitinib or may have affected its pharmacokinetics; the use of food or prescription or nonprescription drugs that are potent inducers or inhibitors of CYP3A4/5 within 7 days or 5 half-lives (whichever was longer) prior to dosing; any clinically significant laboratory abnormality, except for those parameters influenced by hepatic impairment; or significant hepatic encephalopathy (grade $>2$ portal systemic encephalopathy score and severe ascites and/or pleural effusion).

Exclusion criteria for subjects in all groups included a history of febrile illness $\leq 5$ days prior to dosing; any condition, such as gastrectomy, that could affect drug absorption; 12-lead ECG demonstrating corrected QT interval $>450 \mathrm{msec}$ in healthy subjects (i.e., normal hepatic function) and $>470 \mathrm{msec}$ in subjects with mild or moderate hepatic impairment at screening; a history of regular alcohol consumption ( $>7$ drinks/week for females or $>14$ drinks/week for males) within 6 months of screening; and the use of prescription or non-prescription drugs (except acetaminophen $\leq 1 \mathrm{~g} /$ day), vitamins, or dietary supplements within 7 days or 5 half-lives (whichever was longer) prior to dosing in the normal hepatic-function group. Herbal supplements and hormone replacement therapy were to have been discontinued 28 days prior to dosing. Female subjects of childbearing potential, including those with tubal ligation, were not included in the study.

All subjects were required to abstain from grapefruitcontaining products for 7 days prior to and during the study until collection of the final blood sample for pharmacokinetic analysis, strenuous exercise $48 \mathrm{~h}$ prior to and during the study, and alcohol and caffeine consumption $24 \mathrm{~h}$ prior to and during the study. The use of tobacco- or nicotinecontaining products equivalent to $\leq 5$ cigarettes/day was permitted throughout the study period.

This study was performed in accordance with ethical principles originating in or derived from the Declaration of Helsinki and in compliance with the International Conference on Harmonization Good Clinical Practice guidelines and applicable local regulatory requirements and laws. An Institutional Review Board approved the protocol, and all participants gave written informed consent. This trial was registered on ClinicalTrials.gov (NCT00692341).

\section{Axitinib administration}

Subjects with hepatic impairment were admitted to the clinical research unit 2 days before dosing (day-1) in order to obtain a baseline 24-h urine collection for accurate assessment of renal function. Subjects with normal hepatic function were admitted the day before dosing (day 0 ).

Subjects fasted for $\geq 10 \mathrm{~h}$ prior to consumption of a standardized meal on day 1 . The standardized meal consisted of $30 \%$ fat, $15 \%$ protein, and $55 \%$ carbohydrate, equivalent to 500-700 calories, and represented a typical meal consumed by an oncology patient. Subjects received a 5mg single oral dose of axitinib administered as a film-coated immediate-release, dry-granulated tablet within $30 \mathrm{~min}$ of the start of the meal with $240 \mathrm{ml}$ of water. All subjects were required to remain within the clinical research unit until day 3 and return for follow-up visits on days 5 and 7.

Evaluation of axitinib pharmacokinetics

Blood samples $(5 \mathrm{ml})$ were collected in $\mathrm{K}_{3}$-EDTA anticoagulant tubes at $0,0.5,1,1.5,2,2.5,3,4,6,12,16,24,36$, 
48, 96, and $144 \mathrm{~h}$ after the dose of axitinib was administered on day 1 . Separate blood samples $(10 \mathrm{ml})$ in $\mathrm{K}_{3}$-EDTA anticoagulant were also collected on day 1 ( 0 and $4 \mathrm{~h}$ after dosing) for measurement of protein binding of axitinib in plasma. Blood samples for axitinib protein binding were initially scheduled to be collected 0 and $1-2 \mathrm{~h}$ after axitinib dosing (pre- and post-dosing, respectively). However, the observed time to maximum observed concentration of axitinib was delayed in patients with hepatic impairment (occurring $4 \mathrm{~h}$ after dosing). Thus, blood samples collected 0 and $4 \mathrm{~h}$ after dosing were used to determine protein binding of axitinib in plasma. To protect from photodegradation, axitinib in all blood and plasma samples was protected from visible and ultraviolet light exposure during collection, storage, processing, and analysis. Plasma samples were analyzed for axitinib using a high-performance liquid chromatography with tandem mass spectrometric (LC/MS/MS) detection method (Charles River Laboratories, Shrewsbury, MA) validated for accuracy, precision, sensitivity, selectivity, matrix effects, recovery, and stability in compliance with Pfizer standard operating procedures, which conform to the requirements of the FDA bioanalytical method validation guidance [11], as well as a subsequent bioanalytical white paper generated by the FDA and industry representatives [12]. The standard curve was linear with weighted $\left(1 /\right.$ concentration $\left.^{2}\right)$ regression and included nine concentrations in duplicate (range 0.5-100 ng/ml). Each individual standard was within $12 \%$ of nominal concentration, and inter-assay precision at each standard level was within $4 \%$ coefficient of variation $(\mathrm{CV})$. Duplicate quality control (QC) samples at four concentration levels spanning the assay range $(1.5,7.0,40$, and $80 \mathrm{ng} / \mathrm{ml})$ were included in each analytical run to measure assay acceptance. At each QC level, inter-assay accuracy was within 6\% of nominal concentration and inter-assay precision was within $6 \% \mathrm{CV}$

Plasma samples were fortified with deuterium-labeled (d7) axitinib internal standard (IS), followed by addition of $1 \mathrm{M}$ sodium bicarbonate. The samples were extracted with ethyl acetate:hexanes $(75: 25, \mathrm{v} / \mathrm{v})$, centrifuged, and the supernatants were evaporated to dryness under a gentle nitrogen stream in a TurboVap ${ }^{\circledR}$ (Caliper Life Sciences Inc, Waltham, MA) heated to $45^{\circ} \mathrm{C}$. Sample residues were reconstituted in water/methanol/sodium bisulfite/ascorbic acid (75:25:0.5:0.5, v/v/v/v) and eluted from a pentafluorophenylpropyl (F5) column (Discovery HS F5, 50× $2.1 \mathrm{~mm}, 5 \mu \mathrm{m}$ [Supelco, Bellefonte, CA] ) using a gradient of $20-80 \%$ B over $3 \mathrm{~min}$ (mobile phase $\mathrm{A}=10 \mathrm{mM}$ ammonium acetate, mobile phase $\mathrm{B}=$ acetonitrile) at a $0.5 \mathrm{ml} / \mathrm{min}$ flow rate onto an API $3000^{\circledR}$ mass spectrometer (AB Sciex $^{\mathrm{TM}}$, Concord, Ontario, Canada) with electrospray ionization source. Detection was in positive ion mode with multiple reaction monitoring (mass transitions $\mathrm{m} / \mathrm{z} 387 \rightarrow$
356 for axitinib and $394 \rightarrow 360$ for axitinib-d7). Peak areas were quantitated using Analyst ${ }^{\circledR}$ software $\left(A B S\right.$ ciex ${ }^{\mathrm{TM}}$, Concord, Ontario, Canada).

Standard axitinib pharmacokinetic parameters were estimated using non-compartmental methods with Pfizer proprietary software (eNCA). Pharmacokinetic parameters assessed were area under the plasma concentration-time curve (AUC) from time zero to infinity $\left(\mathrm{AUC}_{0-\infty}\right)$, AUC from time zero to time of the last measurable concentration ( $\mathrm{AUC}_{0 \text {-last }}$ ), maximum observed plasma concentration $\left(\mathrm{C}_{\max }\right)$, time to $\mathrm{C}_{\max }, \mathrm{t}_{1 / 2}$, apparent oral clearance $(\mathrm{CL} / \mathrm{F})$, and apparent volume of distribution $(\mathrm{Vz} / \mathrm{F})$.

\section{Evaluation of axitinib protein binding}

Plasma samples were processed to determine axitinib protein binding using an equilibrium dialysis method, and concentrations of resulting unbound and bound axitinib were measured by high-performance LC/MS/MS detection methods (Charles River Laboratories, Shrewsbury, MA) validated in compliance with Pfizer standard operating procedures. Dialysis was performed in a 96-well Teflon dialysis plate (Equilibrium Dialysis Device HTD 96; HTDialysis LLC, Gales Ferry, CT) with wells divided by Spectra/Por ${ }^{\circledR}$-regenerated cellulose membranes with a molecular weight cut-off of 12,000-14,000 Da (Spectrum ${ }^{\circledR}$ Laboratories, Rancho Dominguez, CA). Plasma samples were dialyzed in duplicate against equal volumes of phosphate-buffered saline (70 $\mathrm{mM}$ sodium chloride, $50 \mathrm{mM}$ sodium phosphate, $\mathrm{pH}$ 7.4) for approximately $20 \mathrm{~h}$ at $37^{\circ} \mathrm{C}$ with orbital shaking at $80 \mathrm{rpm}$. Axitinib concentrations in plasma dialysate (representing total bound and unbound axitinib) were measured with the LC/MS/MS assay used for plasma pharmacokinetic samples. Each individual standard was within $10 \%$ of nominal concentration and intra-assay precision at each standard level was within $8 \% \mathrm{CV}$. At each QC level, intra-assay accuracy was within $9 \%$ of nominal concentration and intra-assay precision was within $6 \% \mathrm{CV}$.

Axitinib concentrations in buffer dialysate (representing unbound axitinib) were measured using a validated LC/MS/ MS assay in $\mathrm{K}_{3}$-EDTA plasma "water", an aqueous layer of the supernatant generated by high-speed ultracentrifugation of plasma [13] $\left(440,000 \times g\right.$ for $2.5 \mathrm{~h}$ at $\left.37^{\circ} \mathrm{C}\right)$ using a Beckman TL100 Micro UltraCentrifuge (Beckman Coulter Inc, Brea, CA). The plasma "water" assay had been developed previously and was considered fit-for-purpose for buffer dialysate study sample analysis due to matrix similarity. The standard curve was linear with weighted $\left(1 /\right.$ concentration $\left.^{2}\right)$ regression and included nine concentrations in duplicate (range $20-1,000 \mathrm{pg} / \mathrm{ml}$ ). Each acceptable individual standard was within $13 \%$ of nominal concentration, and intra-assay precision at each standard level was 
within $8 \% \mathrm{CV}(17 \% \mathrm{CV}$ at the lower limit of quantitation). Duplicate QC samples at three concentration levels spanning the assay range $(60,150$, and $800 \mathrm{pg} / \mathrm{ml})$ were included in each analytical run to measure assay acceptance. At each QC level, intra-assay accuracy was within $6 \%$ of nominal concentration and intra-assay precision was within $1 \% \mathrm{CV}$. In addition, QCs consisting of dialyzed plasma:dialyzed buffer $(1: 1, \mathrm{v} / \mathrm{v})$ at concentrations corresponding to low and high areas of the standard curve ( $n=6$ at 60 and $800 \mathrm{pg} / \mathrm{ml}$ ) were included to determine whether the matrix difference between standards and study samples affected quantitation accuracy. For the mixed plasma:buffer QCs, intra-assay accuracy was within $2 \%$ of nominal concentration and intra-assay precision was within $3 \% \mathrm{CV}$ at each QC level.

Buffer dialysate samples were fortified with axitinib-d7 IS, followed by addition of $1 \mathrm{M}$ sodium bicarbonate and $10 \mathrm{mM}$ ammonium acetate aqueous solution (aq). The samples were extracted with ethyl acetate:hexanes $(75: 25, \mathrm{v} / \mathrm{v})$, centrifuged, and the supernatants were evaporated to dryness under a gentle nitrogen stream in a TurboVap heated to $45^{\circ} \mathrm{C}$. Sample residues were reconstituted in water/methanol/sodium bisulfite/ascorbic acid (75:25:0.5:0.5, v/v/v/v) and eluted isocratically with $10 \mathrm{mM}$ ammonium acetate (aq):acetonitrile $(60: 40, \mathrm{v} / \mathrm{v})$ mobile phase over $2 \mathrm{~min}$ from a pentafluorophenylpropyl (F5) column (Discovery HS F5, 50×2.1 mm, $5 \mu \mathrm{m}$ ) at a $0.5 \mathrm{ml} / \mathrm{min}$ flow rate onto an API $4000^{\mathrm{TM}}$ mass spectrometer (AB Sciex ${ }^{\mathrm{TM}}$, Concord, Ontario, Canada) with electrospray ionization source. Detection was in positive ion mode with multiple reaction monitoring (mass transitions $\mathrm{m} / \mathrm{z}$ $387 \rightarrow 356$ for axitinib and $394 \rightarrow 360$ for axitinib-d7). Peak areas were quantitated using Analyst software.

Fraction unbound (fu) was calculated as axitinib in buffer dialysate $(\mathrm{ng} / \mathrm{ml})$ / (axitinib in plasma dialysate $[\mathrm{ng} / \mathrm{ml}]+$ axitinib in buffer dialysate $[\mathrm{ng} / \mathrm{ml}]$ ). Mean fu for each sample was used to calculate pharmacokinetic parameters. Unbound axitinib pharmacokinetic parameters assessed included unbound $\mathrm{AUC}_{0-\infty}$ and $\mathrm{AUC}_{0 \text {-last }}$ (calculated as $A U C_{0-\infty} * f u$ and $A U C_{0-\text { last }} * f u$, respectively), $\mathrm{C}_{\max }$ unbound (calculated as $C_{\max } * f u$ ), unbound $\mathrm{CL} / \mathrm{F}$ (calculated as $C L / F / f u$ ), and unbound $\mathrm{Vz} / \mathrm{F}$ (calculated as $V z / F / f u$ ).

\section{Safety evaluation}

Safety assessments included recording of adverse events, ECGs, blood pressure, pulse rate, clinical laboratory tests (including liver and renal function tests, prothrombin time, and partial thromboplastin time), physical examinations, and vital signs. Blood pressure and pulse rate were measured at screening, pre-dose on day 1 , and at 1,2,16, and $144 \mathrm{~h}$ post dose. A single standard 12-lead ECG was obtained at screening, post dose on day 1 , and at 1.5, 48, and $144 \mathrm{~h}$ post dose.
Statistical methods

Sample size was based on recommendations from the FDA Guidance for Industry on hepatic impairment studies [8]. Pharmacokinetic parameters were estimated by using noncompartmental methods as described above, and summarized by descriptive statistics. Using one-way analysis of variance (ANOVA), natural log-transformed pharmacokinetic parameters $\left(\mathrm{AUC}_{0-\infty}, \mathrm{AUC}_{0 \text {-last }}\right.$, and $\left.\mathrm{C}_{\max }\right)$ were compared between the group of subjects with normal hepatic function and each group of subjects with hepatic impairment. Point estimates and $90 \%$ confidence intervals (CIs) for the differences between these groups on the log scale were constructed then back-transformed to provide estimates of the ratio of adjusted geometric means (i.e., moderate hepatic impairment/normal function and mild hepatic impairment/normal function) and $90 \%$ CIs for the ratios. The differences in pharmacokinetic parameters between subjects with hepatic impairment and with normal hepatic function were evaluated by examination of the ratios and 90\% CIs. Relationships between axitinib exposure and laboratory components of $\mathrm{CP}$ score, including bilirubin, aspartate aminotransferase (AST), alanine aminotransferase (ALT), albumin, and prothrombin time, were assessed graphically and by simple linear regression.

\section{Results}

\section{Predictions from Simcyp modeling}

Using the hepatic impairment model in Simcyp, it was predicted that mild hepatic impairment would increase the axitinib $\mathrm{AUC}_{0-\infty}$, and $\mathrm{C}_{\max }$ by 1.31 - and 1.05 -fold, respectively, compared with normal hepatic function. When axitinib pharmacokinetics in moderate hepatic impairment subjects was simulated, Simcyp predicted a 1.52- and a 1.08fold increase in $\mathrm{AUC}_{0-\infty}$ and $\mathrm{C}_{\max }$, respectively, compared with normal hepatic function. The axitinib $\mathrm{CL} / \mathrm{F}$ predicted for subjects with normal hepatic function by Simcyp modeling using clearance parameters from in vitro experiments with recombinant CYPs was $\sim 8 \mathrm{~L} / \mathrm{h}$, which is approximately threefold lower than what is observed clinically. The predicted 1.52-fold increase in AUC did not warrant the use of a lower axitinib dose in subjects with moderate hepatic impairment compared with those with normal hepatic function given the observed six-fold variability in a previously published healthy volunteers study [14].

Subjects

A total of 24 subjects ( $n=20$ male, 4 female) with a mean age of 51.3 years (range 39.0-60.0) and with normal 
Table 1 Subject baseline demographics

\begin{tabular}{|c|c|c|c|}
\hline & $\begin{array}{l}\text { Normal hepatic } \\
\text { function } \\
(n=8)\end{array}$ & $\begin{array}{l}\text { Mild hepatic } \\
\text { impairment } \\
(n=8)\end{array}$ & $\begin{array}{l}\text { Moderate } \\
\text { hepatic } \\
\text { impairment } \\
(n=8)\end{array}$ \\
\hline $\begin{array}{l}\text { Male/female, } \\
n(\%)\end{array}$ & $\begin{array}{c}7(87.5) / 1 \\
(12.5)\end{array}$ & $\begin{array}{c}7(87.5) / 1 \\
(12.5)\end{array}$ & $\begin{array}{c}6(75.0) / 2 \\
(25.0)\end{array}$ \\
\hline \multicolumn{4}{|l|}{ Age, y } \\
\hline Mean (SD) & $47.4(5.2)$ & $52.5(5.6)$ & $54.3(4.7)$ \\
\hline Range & $39-54$ & $42-58$ & $45-60$ \\
\hline \multicolumn{4}{|c|}{ Ethnicity, $n(\%)$} \\
\hline Black & $2(25.0)$ & 0 & $1(12.5)$ \\
\hline White & $6(75.0)$ & $8(100.0)$ & $7(87.5)$ \\
\hline \multicolumn{4}{|l|}{ Weight, kg } \\
\hline Mean (SD) & $87.4(14.4)$ & $89.4(8.3)$ & $90.3(13.9)$ \\
\hline Range & $60.0-105.9$ & $76.3-100.0$ & $68.2-115.4$ \\
\hline \multicolumn{4}{|l|}{ Height, cm } \\
\hline Mean (SD) & $172.0(8.0)$ & $175.9(6.3)$ & $178.0(9.1)$ \\
\hline Range & $156.0-184.0$ & $162.6-183.0$ & $159.0-188.0$ \\
\hline \multicolumn{4}{|c|}{ Body mass index, $\mathrm{kg} / \mathrm{m}^{2}$} \\
\hline Mean (SD) & $29.3(2.8)$ & $28.9(2.4)$ & $28.4(3.0)$ \\
\hline Range & $24.7-32.6$ & $24.1-30.8$ & $23.9-32.7$ \\
\hline
\end{tabular}

Abbreviation: $S D$ standard deviation hepatic function $(n=8)$ or mild $(n=8)$ or moderate $(n=8)$ hepatic impairment were enrolled in this study. Subject demographics are summarized in Table 1. The mean height, weight, and BMI of all subjects were $89.0 \mathrm{~kg}$ (range 60.0 115.4 ), $175.3 \mathrm{~cm}$ (range 156.0-188.0), and $28.9 \mathrm{~kg} / \mathrm{m}^{2}$ (range 23.9-32.7), respectively. The healthy-subject group was comparable to the two hepatic-impairment groups with respect to weight, age, and gender. All subjects received the 5-mg single oral dose of axitinib and were eligible for pharmacokinetic and safety analysis. There were no discontinuations or withdrawals from the study.

\section{Pharmacokinetics}

The observed clinical plasma pharmacokinetic parameters of axitinib in patients with normal hepatic function or mild or moderate hepatic impairment are summarized in Table 2 and Fig. 1. The plasma concentration-time curves by treatment group are shown in Fig. 2. Overall, subjects with mild hepatic impairment had similar axitinib pharmacokinetics to those with normal hepatic function. However, axitinib exposure was higher among subjects with moderate hepatic impairment compared with subjects with normal hepatic function, as indicated by geometric mean $\mathrm{AUC}_{0-\infty}$ (304 $\mathrm{ng} \mathrm{h} / \mathrm{ml}[\% \mathrm{CV} 44]$ vs. $156 \mathrm{ng} \mathrm{h} / \mathrm{ml}[\% \mathrm{CV}$ 63],

Table 2 Pharmacokinetic parameters of axitinib following administration of a single 5-mg oral dose in subjects with normal hepatic function or mild or moderate hepatic impairment

\begin{tabular}{|c|c|c|c|}
\hline Pharmacokinetic parameter & $\begin{array}{l}\text { Normal hepatic function } \\
(n=8)\end{array}$ & $\begin{array}{l}\text { Mild hepatic impairment } \\
(n=8)\end{array}$ & $\begin{array}{l}\text { Moderate hepatic impairment } \\
(n=8)\end{array}$ \\
\hline $\mathrm{AUC}_{0-\infty}(\mathrm{ng} \mathrm{h} / \mathrm{ml})^{\mathrm{a}}$ & $156(63)$ & $122(167)$ & $304(44)$ \\
\hline $\operatorname{AUC}_{0 \text {-last }}(\mathrm{ng} \mathrm{h} / \mathrm{ml})^{\mathrm{a}}$ & $148(69)$ & $116(180)$ & $295(44)$ \\
\hline $\mathrm{CL} / \mathrm{F}(\mathrm{L} / \mathrm{hr})^{\mathrm{a}}$ & $32.1(63)$ & $40.9(167)$ & $16.4(44)$ \\
\hline $\mathrm{C}_{\max }(\mathrm{ng} / \mathrm{ml})^{\mathrm{a}}$ & $30.4(50)$ & $27.0(127)$ & $38.8(50)$ \\
\hline $\mathrm{T}_{\max }(\mathrm{h})^{\mathrm{b}}$ & $3.5(2.0-4.0)$ & $2.75(1.0-4.0)$ & $4.0(1.5-4.0)$ \\
\hline $\mathrm{Vz} / \mathrm{F}(\mathrm{L})^{\mathrm{a}}$ & $166(52)$ & $163(87)$ & $128(67)$ \\
\hline$t_{1 / 2}(h)^{c}$ & $4.74(80)$ & $3.61(84)$ & $7.12(91)$ \\
\hline Fraction unbound ${ }^{\mathrm{a}}$ & $0.004049(25)$ & $0.002987(50)$ & $0.004083(134)$ \\
\hline $\mathrm{AUC}_{0-\infty, \text { unbound }}(\mathrm{ng} \mathrm{h} / \mathrm{ml})^{\mathrm{a}}$ & $0.630(56)$ & $0.689(82)$ & $1.241(109)$ \\
\hline $\mathrm{AUC}_{0 \text {-last, unbound }}(\mathrm{ng} \mathrm{h} / \mathrm{ml})^{\mathrm{a}}$ & $0.601(61)$ & $0.671(81)$ & $1.206(106)$ \\
\hline $\mathrm{C}_{\max , \text { unbound }}(\mathrm{ng} / \mathrm{ml})^{\mathrm{a}}$ & $0.123(46)$ & $0.132(47)$ & $0.159(97)$ \\
\hline $\mathrm{CL} / \mathrm{F}$ unbound $(\mathrm{L} / \mathrm{hr})^{\mathrm{a}}$ & $7933(56)$ & $7253(82)$ & 4029 (109) \\
\hline $\mathrm{Vz} / \mathrm{F}$ unbound $(\mathrm{L})^{\mathrm{a}}$ & $41,109(57)$ & $42,378(40)$ & $31,269(121)$ \\
\hline
\end{tabular}

Abbreviations: $A U C_{0-\infty}$ area under the concentration-time curve (AUC) from time zero to infinity, $A U C_{0-l a s t}$ AUC from time zero to time of the last measurable concentration, $A U C_{0-\infty}$, unbound $\mathrm{AUC}$ for unbound drug from time zero to infinity, $A U C_{0-\text { last, unbound }} \mathrm{AUC}$ for unbound drug from time zero to time of the last measurable concentration, $C L / F$, apparent oral clearance, $C L / F_{\text {unbound }}$ apparent oral clearance of unbound drug, $C_{\max }$ maximum observed plasma concentration, $C_{\max }$, unbound maximum observed plasma concentration for unbound drug, $t_{1 / 2}$ half life, $T_{\max }$ time to maximum observed plasma concentration, $V z / F$ apparent volume of distribution, $V z / F_{\text {unbound }}$ apparent volume of distribution for unbound drug

${ }^{\text {a }}$ Geometric mean (\% coefficient of variation $[\mathrm{CV}]$ around the geometric mean)

b Median (range)

c Arithmetic mean (\% CV around the arithmetic mean) 


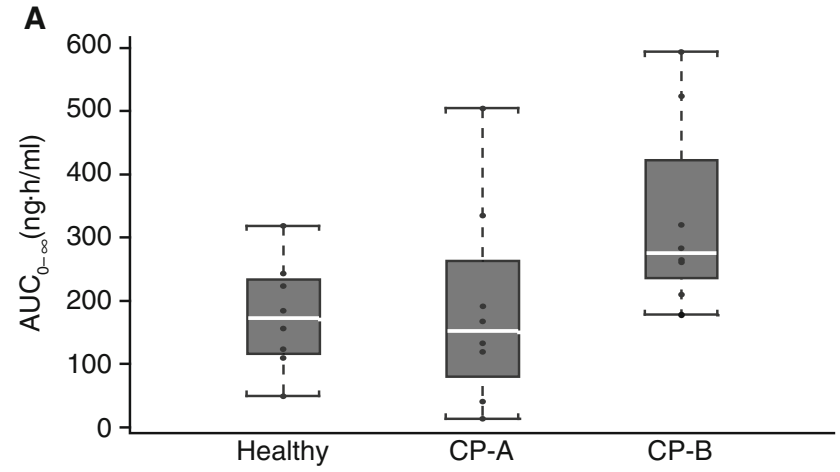

B
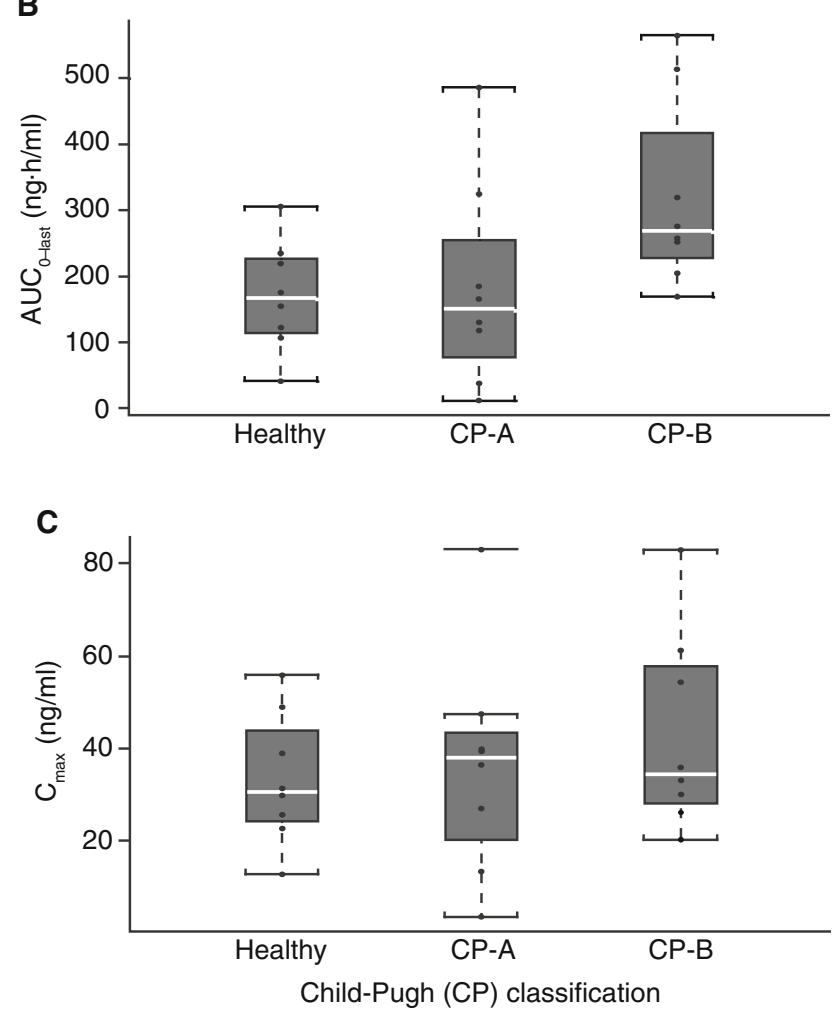

Fig. 1 Axitinib plasma exposure by treatment group for a area under the concentration-time curve (AUC) from time zero to infinity $\left(\mathrm{AUC}_{0-\infty}\right)$, b AUC from time zero to time of the last measurable concentration $\left(\mathrm{AUC}_{0 \text {-last }}\right)$, and $\mathbf{c}$ maximum observed plasma concentration $\left(\mathrm{C}_{\max }\right)$

respectively) and $\mathrm{C}_{\max }(38.8 \mathrm{ng} / \mathrm{ml}[\% \mathrm{CV} 50]$ vs. $30.4 \mathrm{ng} / \mathrm{ml}$ [\% CV 50]), respectively.

Log-transformed pharmacokinetic parameters were compared using ANOVA. The adjusted geometric means ratio for $\mathrm{AUC}_{0-\infty}$ and $\mathrm{C}_{\max }$ in subjects with mild hepatic impairment compared with normal hepatic function was $78.34 \%(90 \%$ CI $39.92-153.75)$ and $88.61 \%(90 \%$ CI 49.20-159.56), respectively. The adjusted geometric means ratio for $\mathrm{AUC}_{0-\infty}$ and $\mathrm{C}_{\max }$ in subjects with moderate hepatic impairment compared with normal hepatic function was $195.25 \%(90 \%$ CI $99.49-383.18)$ and $127.67 \%(90 \%$ CI 70.90-229.91), respectively.
Protein binding

Results of the protein-binding analysis are summarized in Table 2. Approximately $0.3 \%$ to $0.4 \%$ of axitinib was unbound in plasma in the subjects with varying hepatic function assessed in this study. The geometric means for the fraction unbound in plasma for axitinib were similar among treatment groups. The adjusted geometric mean ratio for fraction unbound in subjects with mild hepatic impairment compared with normal hepatic function was $73.78 \%(90 \%$ CI 37.40-145.56). The adjusted geometric mean ratio for fraction unbound in subjects with moderate hepatic impairment compared with normal hepatic function was $100.86 \%$ (90\% CI 55.58-183.02).

Overall, the results for the unbound pharmacokinetic parameters mimicked those for total pharmacokinetic parameters (Table 2). The axitinib geometric mean $(\% \mathrm{CV}$ for geometric mean) plasma $\mathrm{C}_{\max }$, unbound values were similar in subjects with normal hepatic function and mild hepatic impairment. Likewise, axitinib geometric mean plasma $\mathrm{AUC}_{0-\infty}$, unbound values and geometric mean $\mathrm{AUC}_{0 \text {-last, unbound }}$ parameter estimates were similar in subjects with normal hepatic function and mild hepatic impairment, but were higher in those with moderate hepatic impairment (Table 2).

\section{Clinical correlations of laboratory parameters}

The relationship between axitinib exposure and laboratory parameters that are components of the $\mathrm{CP}$ classification system, such as albumin, AST, ALT, bilirubin, and prothrombin time, were explored. When axitinib plasma exposure (indicated by plasma AUC) was assessed in relation to measures of liver function, there were marginal trends for axitinib AUC to increase with lower serum albumin $\left(r^{2}=0.14\right.$; $p=0.0644)$, higher AST $\left(r^{2}=0.10 ; p=0.1028\right)$, higher ALT $\left(r^{2}=0.02 ; p=0.4969\right)$, and higher bilirubin $\left(r^{2}=0.13 ; p=\right.$ 0.0710 ) (Fig. 3). Increased axitinib exposure was also associated with higher prothrombin time $\left(r^{2}=0.11 ; p=\right.$ $0.1067)$. These trends did not reach statistical significance. When axitinib AUC was evaluated according to smoking status, the median exposures were 200, 236, and $263 \mathrm{ng} \mathrm{h} / \mathrm{ml}$, respectively, for non-smokers, active smokers, and exsmokers (i.e., not actively smoking at the time of screening who would refrain from smoking throughout the study period). Weak correlations between the fraction unbound in plasma of axitinib and both plasma albumin and bilirubin concentrations were observed (data not shown).

Safety

Adverse events The 5-mg single dose of axitinib was well tolerated in subjects with mild or moderate hepatic 


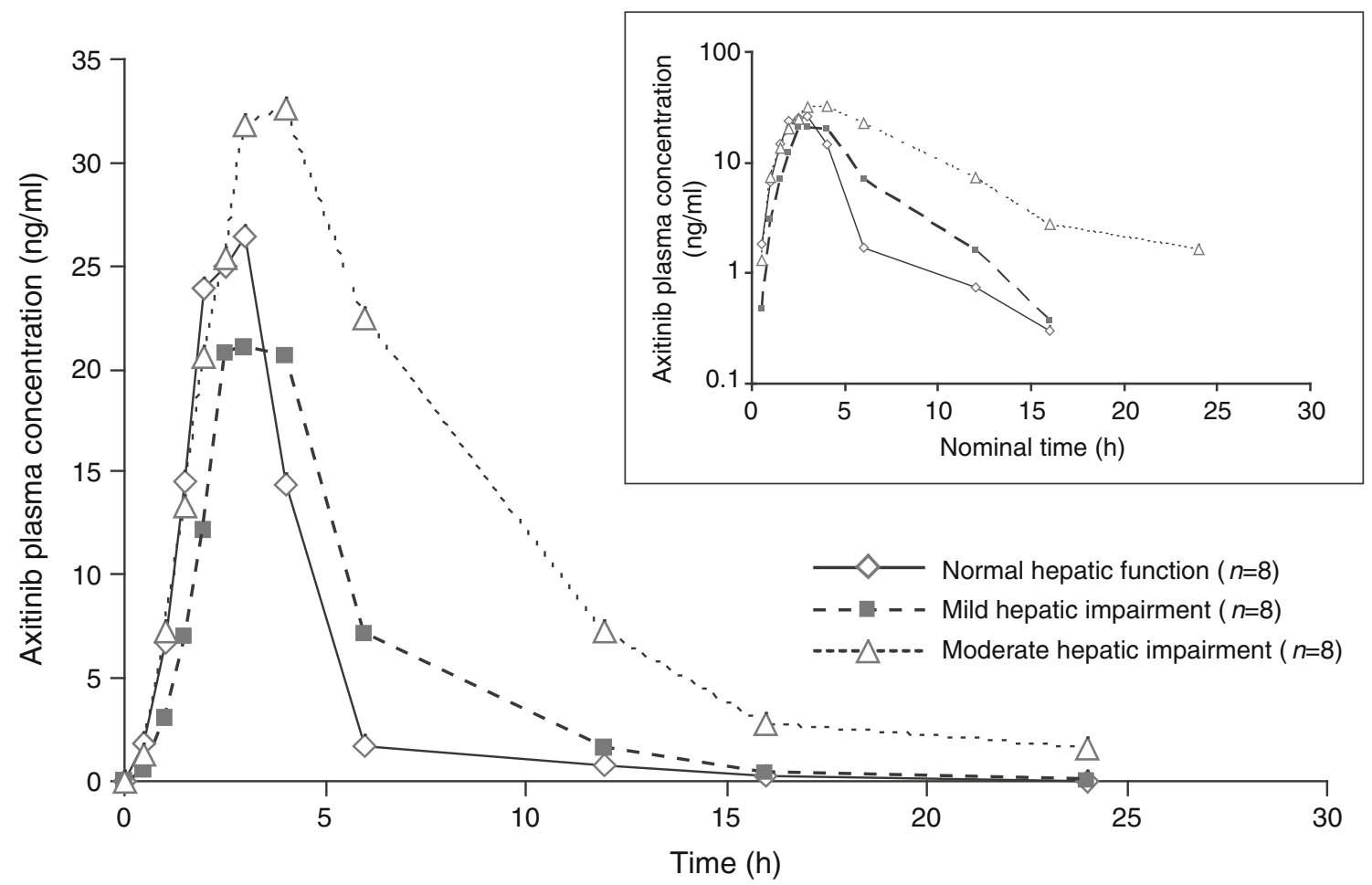

Fig. 2 Median plasma concentration-time plot for axitinib by treatment group. Inset shows data on log-scale

impairment or normal hepatic function. There were no deaths, serious adverse events, or discontinuations due to study treatment. A total of four adverse events were reported in three subjects in the group with normal hepatic function, including headache $(n=1)$ and lethargy $(n=3)$. The three adverse events of lethargy were considered to be treatmentrelated, were mild or moderate in nature, and resolved without treatment. No adverse events were reported in the mild or moderate hepatic-impairment groups.

Laboratory parameters The incidence of laboratory abnormalities was low, and no clinically important trends were observed. No laboratory abnormalities were reported as adverse events. There were a total of 13 reports of laboratory abnormalities, 8 of which were also reported at baseline ( 2 with normal hepatic function, 3 with mild hepatic impairment, and 8 with moderate hepatic impairment). In the healthy-subject group, there was one report each of urine white blood cell count $\geq 6$ /high power field (HPF) and urine hyaline casts $>1 /$ low power field (LPF). In the mild hepatic-impairment group, there was one report each of urine protein $\geq 1$, urine protein/hemoglobin $\geq 1$, and urine hyaline casts $>1 / \mathrm{LPF}$. In the moderate hepaticimpairment group, there was one report each of eosinophil $\%>1.2$ times upper limit of normal (ULN), absolute monocyte count 1.2 times ULN, urine white blood cell count $\geq 6 / \mathrm{HPF}$, urine glucose $\geq 1$, urine hyaline casts $>1 / \mathrm{LPF}$, and urine granular casts $>1 / \mathrm{LPF}$, and two reports of urine protein $\geq 1$.

Vital signs There were no clinically significant changes in vital signs or ECGs. An increase in post-baseline systolic and diastolic blood pressure was observed for some subjects in the mild and moderate hepatic-impairment groups (mean increases of $24.9 \mathrm{~mm} \mathrm{Hg}$ and $14.8 \mathrm{~mm} \mathrm{Hg}$, systolic and diastolic blood pressure, respectively, $16 \mathrm{~h}$ post dosing), but blood pressures returned to near baseline levels at the next collection time point on day 7. Transient and reversible increases in blood pressure following axitinib single-dose administration have been noted in previous studies of healthy volunteers.

\section{Discussion}

The results from this study demonstrate three important findings. First, moderate hepatic impairment increased the exposure $\left(\mathrm{AUC}_{0-\infty}\right.$ and $\mathrm{C}_{\max }$ ) of axitinib compared with normal hepatic function; however, mild hepatic impairment did not change these pharmacokinetic parameters. Second, there were no overt changes in plasma protein binding of axitinib among the three subject groups. Third, a 5-mg single oral dose of axitinib was well tolerated in subjects 

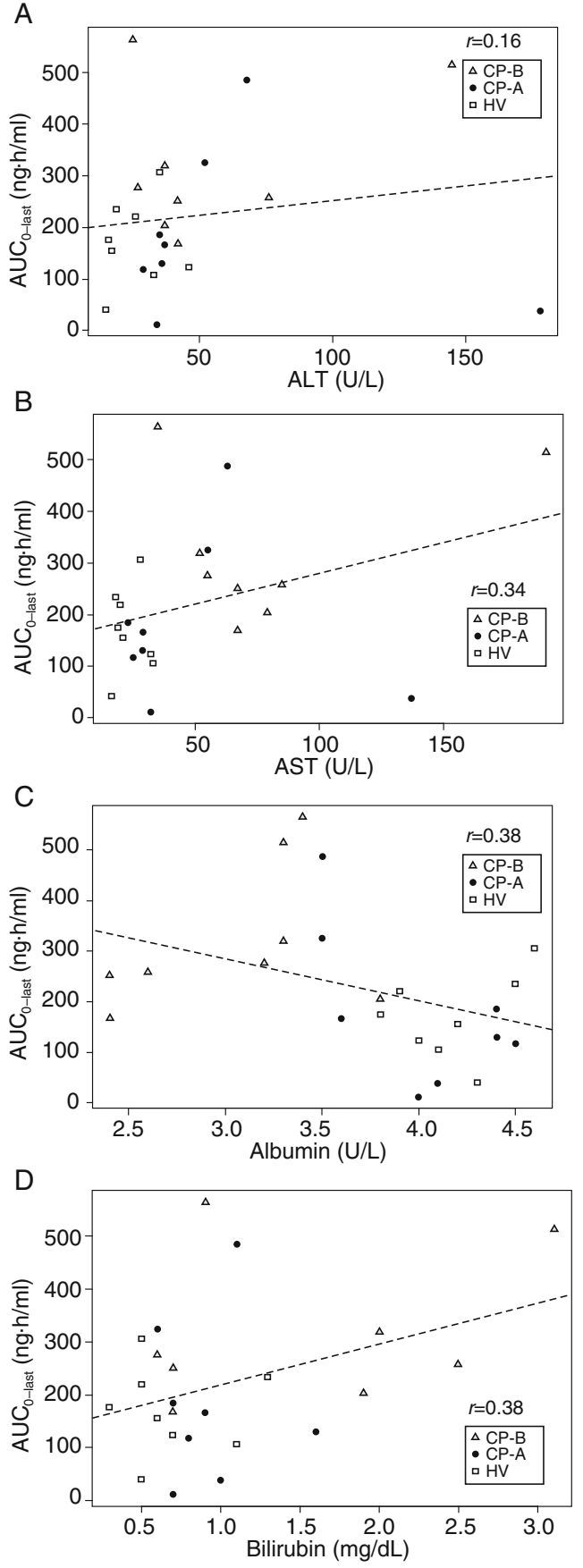

Fig. 3 Correlation between measures of hepatic function and axitinib exposure determined by area under the concentration-time curve from time zero to time of the last measurable concentration $\left(\mathrm{AUC}_{0 \text {-last }}\right)$ for $\mathbf{a}$ alanine aminotransferase (ALT), b aspartate aminotransferase (AST), $\mathbf{c}$ serum albumin, and $\mathbf{d}$ bilirubin. Abbreviations: $C P$ Child-Pugh class, $H V$ healthy volunteers

with mild or moderate hepatic impairment and in those with normal hepatic function.

The impact of hepatic impairment on the pharmacokinetics and disposition of drugs as well as on their efficacy and tolerability is well known, and is of particular importance in identifying patient populations that may be at increased risk for toxicity. Both the FDA and the European Medicines Agency have issued guidelines for the evaluation of the pharmacokinetics of drugs in clinical development in patients with impaired hepatic function $[8$, 15]. In this study, following administration of a 5-mg single oral dose of axitinib, the pharmacokinetics was not affected by mild hepatic impairment (CP-A). However, axitinib plasma exposure was increased approximately two-fold by moderate hepatic impairment (CP-B) compared with normal hepatic function.

The primary route of elimination for axitinib is via hepatobiliary excretion. Axitinib has an estimated low hepatic extraction ratio in humans $(\sim 0.3$, computed from observed systemic clearance after an intravenous dose to humans, experimentally observed blood-to-plasma ratio for axitinib, and theoretical hepatic blood flow in humans) and a high degree of plasma protein binding ( $>99 \%$ bound). Based on the well-stirred model of hepatic clearance, the hepatic clearance of a low-extraction drug would be assumed to be the product of the intrinsic clearance and fraction unbound in plasma [16-18]. For low-extraction drugs with high plasma protein binding $(\geq 90 \%)$, the free fraction of drug is typically increased in patients with liver cirrhosis, which is associated with an increase in plasma clearance $[19,20]$. No overt changes in protein binding of axitinib in subjects with mild or moderate hepatic impairment were observed in this study and, therefore, the changes in exposure are likely due to a change in the intrinsic clearance. This is probably associated with lowered metabolic capacity in subjects with moderate impairment or shunting of hepatic blood flow resulting in drug bypassing the hepatic parenchymal cells (with metabolic enzymes).

Mechanisms for decreases in binding of drugs to plasma proteins with hepatic impairment include (1) changes in albumin synthesis, leading to lower levels of plasma albumin, and (2) accumulation of endogenous compounds such as bilirubin [21]. Expectedly, subjects with moderate impairment in this study had higher baseline bilirubin values compared with subjects in the mild-impairment group. Also, subjects with moderate hepatic impairment had lower serum baseline albumin levels compared with subjects with mild impairment. However, this did not translate into a meaningful change in plasma protein binding for axitinib; there were no overt changes in fraction unbound in plasma among the three groups assessed in the study. Presumably the altered lab parameters for albumin and bilirubin with hepatic impairment were not sufficient to elicit a change in fraction unbound for a drug (e.g., axitinib) that is highly protein bound ( $>99 \%)$. Further, the detection of minor changes in protein binding may be limited by the current bioanalytical methodology as well as the variability seen in protein binding between subjects. In addition, weak 
correlations were found between axitinib exposure and clinical laboratory parameters that are typical measures of hepatic function, including AST, ALT, albumin, bilirubin, and prothrombin time. Since axitinib is metabolized by CYP1A2, albeit to a minor extent, relationships with smoking status were also evaluated since smoking has been shown to induce CYP1A2 [22]. Although only a small number of patients were evaluated, the study results indicated that axitinib exposure was similar in nonsmokers, active smokers, and ex-smokers. Smoking status is being evaluated as a covariate for axitinib exposure in ongoing population pharmacokinetic analyses from multiple axitinib trials.

While the observed changes in axitinib pharmacokinetics with hepatic impairment did not precisely match those predicted by Simcyp, they were in general agreement, particularly for the moderate-impairment group. It should be noted that the Simcyp predictions for axitinib pharmacokinetics in subjects with normal hepatic function resulted in overprediction of the plasma exposures compared with what is observed clinically. The reasons for the differences between Simcyp-predicted and clinically observed data could be ascribed to the selected input parameters in the hepatic-impairment model used by the software and built-in standard physiological parameters used for the simulations. While the existing input parameters based on in vitro data underestimated the clinical plasma clearance for axitinib (Simcyp CL/F estimation of $8 \mathrm{~L} / \mathrm{h}$ vs. observed human $\mathrm{CL} / \mathrm{F} \sim 24 \mathrm{~L} / \mathrm{h}$ ), it was still able to reasonably predict the expected fold change in exposures with hepatic impairment. Overall, Simcyp-predicted 1.3- to 1.5-fold higher exposures expected with mild and moderate impairment and provided confidence in the selection of a 5-mg single dose for this clinical study when it was being designed, which was based on the previous safe administration of up to six-fold higher (i.e., $30 \mathrm{mg}$ ) single doses of axitinib in patients [6]. These results support the use of in silico modeling tools such as Simcyp to aid in the design of clinical studies.

This study also demonstrated that a single dose of axitinib was well tolerated in subjects with hepatic impairment, with no adverse events reported in either the mild- or moderate-impairment groups. Three treatmentrelated adverse events were reported during this study, all of which occurred in the group with normal hepatic function. These were mild or moderate events and resolved without further treatment. This study does not address the safety and tolerability of axitinib in cancer patients with hepatic impairment, but the data reported here may be used to guide dosing in these patients.

While the exact change in axitinib plasma exposure anticipated in subjects with severe hepatic impairment (CP-C) was not evaluated in this study, it can be reasonably expected to exceed or equal changes observed in subjects with moderate hepatic impairment (CP-B). In ongoing studies of axitinib in patients with solid tumors, subjects are required to have adequate hepatic function at the time of study entry. However, for patients who might develop hepatic impairment during axitinib treatment, the results of this study indicate the need for appropriate dose reduction, particularly when the extent of hepatic impairment approaches moderate impairment as defined by CP criteria. Ongoing studies in cancer patients will provide guidance on appropriate dose reductions for axitinib based on observed safety profiles of individual patients. These study results indicate the need for particular attention to dose adjustments in patients who develop moderate (or worse) hepatic impairment.

Acknowledgments Editorial support was provided by Joanna Bloom, PhD, at UBC Scientific Solutions (Southport, CT, USA) and Adam McGechan at ACUMED ${ }^{\circledR}$ (Tytherington, UK) and was funded by Pfizer Inc. This study was sponsored by Pfizer Inc.

Open Access This article is distributed under the terms of the Creative Commons Attribution Noncommercial License which permits any noncommercial use, distribution, and reproduction in any medium, provided the original author(s) and source are credited.

\section{References}

1. Hu-Lowe DD, Zou HY, Grazzini ML, Hallin ME, Wickman GR, Amundson K, Chen JH, Rewolinski DA, Yamazaki S, Wu EY, McTigue MA, Murray BW, Kania RS, O'Connor P, Shalinsky DR, Bender SL (2008) Nonclinical antiangiogenesis and antitumor activities of axitinib (AG-013736), an oral, potent, and selective inhibitor of vascular endothelial growth factor receptor tyrosine kinases 1, 2, 3. Clin Cancer Res 14:7272-7283. doi:10.1158/1078-0432.CCR-08-0652

2. Rixe O, Bukowski RM, Michaelson MD, Wilding G, Hudes GR, Bolte O, Motzer RJ, Bycott P, Liau KF, Freddo J, Trask PC, Kim S, Rini BI (2007) Axitinib treatment in patients with cytokinerefractory metastatic renal-cell cancer: a phase II study. Lancet Oncol 8:975-984. doi:10.1016/S1470-2045(07)70285-1

3. Rini BI, Wilding G, Hudes G, Stadler WM, Kim S, Tarazi J, Rosbrook B, Trask PC, Wood L, Dutcher JP (2009) Phase II study of axitinib in sorafenib-refractory metastatic renal cell carcinoma. J Clin Oncol 27:4462-4468. doi:10.1200/JCO.2008.21.7034

4. Cohen EE, Rosen LS, Vokes EE, Kies MS, Forastiere AA, Worden FP, Kane MA, Sherman E, Kim S, Bycott P, Tortorici M, Shalinsky DR, Liau KF, Cohen RB (2008) Axitinib is an active treatment for all histologic subtypes of advanced thyroid cancer: results from a phase II study. J Clin Oncol 26:4708-4713. doi:10.1200/JCO.2007.15.9566

5. Schiller JH, Larson T, Ou SH, Limentani S, Sandler A, Vokes E, Kim S, Liau K, Bycott P, Olszanski AJ, von Pawel J (2009) Efficacy and safety of axitinib in patients with advanced nonsmall-cell lung cancer: results from a phase II study. J Clin Oncol 27:3836-3841. doi:10.1200/JCO.2008.20.8355

6. Rugo HS, Herbst RS, Liu G, Park JW, Kies MS, Steinfeldt HM, Pithavala YK, Reich SD, Freddo JL, Wilding G (2005) Phase I trial of the oral antiangiogenesis agent AG-013736 in patients with advanced solid tumors: pharmacokinetic and clinical results. J Clin Oncol 23:5474-5483. doi:10.1200/JCO.2005.04.192 
7. Jamei M, Marciniak S, Feng K, Barnett A, Tucker G, RostamiHodjegan A (2009) The Simcyp((R)) Population-based ADME Simulator. Expert Opin Drug Metab Toxicol Feb 6 [Epub ahead of print] doi: $10.1517 / 17425250802691074$

8. US Department of Health and Human Services Food and Drug Administration (2003) Guidance for industry pharmacokinetics in patients with impaired hepatic function: study design, data analysis, and impact on dosing and labeling. US Food and Drug Administration Center for Drug Evaluation and Research. http:// www.fda.gov/downloads/Drugs/GuidanceComplianceRegulator yInformation/Guidances/ucm072123.pdf. Accessed 2 November 2009

9. Child CG, Turcotte JG (1964) Surgery and portal hypertension. In: Child CG (ed) The liver in portal hypertension. WB Saunders, Philadelphia, pp 50-52

10. Pugh RN, Murray-Lyon IM, Dawson JL, Pietroni MC, Williams R (1973) Transection of the oesophagus for bleeding oesophageal varices. Br J Surg 60:646-649

11. U.S. Department of Health and Human Services Food and Drug Administration CfDEaRC, Center for Veterinary Medicine (CVM) (2001) Guidance for industry bioanalytical method validation. US Food and Drug Administration Center for Drug Evaluation and Research. http://www.fda.gov/downloads/Drugs/Guidance ComplianceRegulatoryInformation/Guidances/ucm070107.pdf. Accessed 24 May 2010

12. Viswanathan CT, Bansal S, Booth B, DeStefano AJ, Rose MJ, Sailstad J, Shah VP, Skelly JP, Swann PG, Weiner R (2007) Quantitative bioanalytical methods validation and implementation: best practices for chromatographic and ligand binding assays. AAPS J 9:E30-42. doi:10.1208/aapsj0901004

13. Nakai D, Kumamoto K, Sakikawa C, Kosaka T, Tokui T (2004) Evaluation of the protein binding ratio of drugs by a micro-scale ultracentrifugation method. J Pharm Sci 93:847-854. doi:10.1002/ jps. 20012

14. Pithavala YK, Tortorici M, Toh M, Garrett M, Hee B, Kuruganti U, Ni G, Klamerus KJ (2010) Effect of rifampin on the pharmacokinetics of Axitinib (AG-013736) in Japanese and
Caucasian healthy volunteers. Cancer Chemother Pharmacol 65:563-570. doi:10.1007/s00280-009-1065-y

15. European Medicines Agency (2005) Guideline on the evaluation of the pharmacokinetics of medicinal products in patients with impaired hepatic function. EMEA (European Medicines Agency) Web site. http://www.emea.europa.eu/pdfs/human/ewp/23390en. pdf. Accessed 2 November 2009

16. Pang KS, Rowland M (1977) Hepatic clearance of drugs. I. Theoretical considerations of a "well-stirred" model and a "parallel tube" model. Influence of hepatic blood flow, plasma and blood cell binding, and the hepatocellular enzymatic activity on hepatic drug clearance. J Pharmacokinet Biopharm 5:625-653

17. Pang KS, Rowland M (1977) Hepatic clearance of drugs. II. Experimental evidence for acceptance of the "well-stirred" model over the "parallel tube" model using lidocaine in the perfused rat liver in situ preparation. J Pharmacokinet Biopharm 5:655-680

18. Pang KS, Rowland M (1977) Hepatic clearance of drugs. III. Additional experimental evidence supporting the "well-stirred" model, using metabolite (MEGX) generated from lidocaine under varying hepatic blood flow rates and linear conditions in the perfused rat liver in situ preparation. J Pharmacokinet Biopharm 5:681-699

19. MacKichan JJ (2006) Influence of protein binding and use of unbound (free) drug concentrations. In: Burton ME, Shaw LM, Schentag JJ, Evans WE (eds) Applied pharmacokinetics \& pharmacodynamics - principles of therapeutic drug monitoring. Lippincott Williams \& Wilkins, Philadelphia, pp 82-120

20. Blaschke TF (1977) Protein binding and kinetics of drugs in liver diseases. Clin Pharmacokinet 2:32-44

21. Verbeeck RK (2008) Pharmacokinetics and dosage adjustment in patients with hepatic dysfunction. Eur J Clin Pharmacol 64:11471161. doi:10.1007/s00228-008-0553-Z

22. Sesardic D, Boobis AR, Edwards RJ, Davies DS (1988) A form of cytochrome $\mathrm{P} 450$ in man, orthologous to form $\mathrm{d}$ in the rat, catalyses the O-deethylation of phenacetin and is inducible by cigarette smoking. Br J Clin Pharmacol 26:363-372 